\title{
A Framework for a Post-2012 Global Climate Agreement
}

\section{Introduction}

Global greenhouse gas emissions are on a steeper growth trajectory than assumed in most scenarios that underlie current international policy discussions and negotiations. ${ }^{1}$ Effective global climate change mitigation action will require speed, depth and breadth well beyond any efforts seen to date, and will need to involve all major emitters, including developing countries (Garnaut et al., 2008). To achieve a comprehensive global agreement at or after the Copenhagen climate conference, a principles-based framework for mitigation is needed. Here we outline a system that adds up to a global solution, and that could be broadly acceptable. It involves internationally tradable emissions rights allocated across countries, with allocations moving over time to equal per capita allocations. Developing countries would receive increasing emissions entitlements, linked to their GDP growth, for a transitional period. Binding emissions targets would apply to all developed and high-income countries plus China from the outset. Other developing countries, but not least developed countries, would be required to take on one-

Ross Garnaut is Vice-Chancellor's Fellow and Professorial Fellow in Economics at the University of Melbourne and Distinguished Professor at the Australian National University, a Fellow of the Australian Academy of Social Sciences, Honorary Professor of the Chinese Academy of Social Science, and chairman of a number of boards. He conducted the Garnaut Climate Change Review for Australian governments, concluded in September 2008.

Frank Jotzo is Research Fellow at the Research School of Pacific and Asian Studies at the Australian National University, and has worked on the economics and policy of climate change for the last decade. He was economic advisor with the Garnaut Review.

Stephen Howes is Professorial Fellow at the Crawford School of Economics and Government at the Australian National University, and formerly Chief Economist at AusAID and a lead economist with the World Bank. He was manager of the international work stream for the Garnaut Review. sided targets below their business-as-usual trajectory, and they would expect to benefit from international trade in allocations. Additional building blocks would be commitments by highincome countries to invest in low-emissions technologies and to provide additional assistance for climate change adaptation in developing countries, and sectoral agreements to place a comparable carbon price on emissions-intensive, trade-exposed industries in all countries.

\section{Why quantitative commitments?}

Any agreement on a global goal for climate change mitigation requires that effort to be distributed among countries. Any agreement will arise from negotiations involving in particular the major emitters, especially China and the United States, but there are basic principles that would facilitate agreement. The first choice to make is what form national level commitments should take, with the main alternatives being price-based and quantity-based commitments (see Garnaut, 2008, chapter 9 for an extended discussion). Pricebased commitments would involve setting an internationally agreed tax rate on greenhouse gas emissions (Cooper, 2000; Nordhaus, 2008), or hybrid systems with quantitative caps that have a government-backed price cap as an override (McKibbin and Wilcoxen, 2002; Pizer, 2002).

The main argument for price control is the inevitable uncertainty about the costs of reaching any particular quantitative emissions outcome. Other arguments in favour of agreements on prices are that international financial flows and the question of distribution of effort between countries would be avoided, that transaction costs would be low and political distortions limited. On the other hand, tax rates would need to be adjusted from time to time in light of the emissions reductions achieved, and in light of new scientific knowledge that might demand limitation of emissions to defined levels, for example to avoid specific tipping points in the climate system if they can be identified. 
Ultimately, a quantity-based system of commitments, or 'cap-and-trade', is more likely to succeed at the international level than a price-based one, for a number of reasons.

First, it builds on existing international structures. The Kyoto Protocol, though nowhere near as effective as needed, did establish an architecture around emissions targets, and quantitative targets frame the current negotiations about a post-2012 framework. The urgency of the climate challenge argues for building on existing efforts, not overturning them. Second, the option to differentiate efforts, and to trade emissions rights internationally, can provide a strong incentive for developing countries to come on board. Differentiation under cap-and-trade is possible without sacrificing efficiency, because differentiated targets do not affect the common international price that prevails under trading. Third, quantitative targets control emissions levels more directly than taxes, and are thus more easily communicated. Fourth, they can be implemented with flexibility over time to avoid cost blow-outs. And finally, emissions target commitments retain countries' freedom to implement whatever mix of policies they choose domestically, in contrast to an agreement on a specific tax rate. Also, international comparison and verification of tax effort across countries would be fraught.

\section{A principle for allocating emissions entitlements}

The crucial question in any cap-and-trade system is how emissions entitlements are allocated, and it is the question on which a future international climate agreement is going to swim or sink. The Kyoto Protocol allocated emissions entitlements essentially on an ad hoc basis, with a narrow range of differentiation around 1990 base years. An approach like that would be unacceptable to most developing countries, as it locks in historical patterns of usage of the atmosphere, which are strongly skewed in favour of current developed countries. Developed countries account for most of the anthropogenic greenhouse gases already in the atmosphere, while developing countries on average and in most cases have relatively low levels of emissions per person, but strongly growing populations and economies.

This implies that emissions entitlements in developing countries would need to continue growing for some time, albeit at a slower rate than would be the case without climate change mitigation, while rich countries' entitlements would need to fall.

Any system for differentiating the global effort that is put forward in earnest needs to add up to a global total that limits the risk of climate change to acceptable levels. Formulas can be devised that coincide with the interests of any particular nation, but they will not be broadly acceptable elsewhere. By contrast, principles that are broadly acceptable and can garner support from heads of government in the lead-up to the 2009 Copenhagen climate conference need to be simple, transparent and readily applicable. They will need to be seen as fair, and that will mean that they will need to give much weight to population, acknowledging the stark differences in per capita emissions between developed and developing countries that exist today. And they will need to be seen as practical, which implies long periods of adjustment towards population-based allocations.

Various proposals for differentiating targets have been made, for example around principles of responsibility and capacity and effort (see discussion in Garnaut, 2008, chapter 9). However, many of these approaches include complex or contestable indicators and computations. It is difficult to see how broad international agreement about what is equitable, especially in the longer term, could be formed in anything but a very simple framework.

The only approach that seems to have a sufficient degree of perceived fairness as well as practicality is a gradual move to equal per capita emissions entitlements, starting from the status quo. Anything but a move to equal per capita allocations would not be acceptable to most developing countries. In fact, a gradual move to equal per capita allocations may be seen as unduly favouring current and past high per capita emitters, as it does not address the issue of historical responsibility. International funding for climate change mitigation by developed countries, discussed further below, would provide additional support to developing countries (as suggested by Bhagwati, 2006) and help make a gradual shift to equal per capita allocations defendable.

The per capita principle may seem challenging in developed countries that currently have well above global average per capita emissions, including Australia and New Zealand. Yet it is broadly consistent with the emerging longerterm emissions goals of developed countries. For example, the mid-century emissions goals announced or anticipated for the United Kingdom, Japan and the United States equate to per capita emissions of between 3 and 5 tonnes. They are much below current levels in these countries of between 11 (UK, Japan) and 22 tonnes (US) per person, below the current global average of 6 tonnes per person, and close to the $2-3$ tonnes per capita average implied by stabilisation scenarios put forward by the Intergovernmental Panel on Climate Change, together with United Nations population projections.

Importantly, the actual effort required by a move to equal per capita allocations compared to targets framed in absolute terms relates not just to the starting levels of per capita emissions, but also to the rate of population growth. Countries with high per capita emissions but growing populations, such as Australia, but also the US and Canada, will find that their population growth reduces the extent of emissions reductions which receive greater absolute allocations if emissions targets are framed in per capita terms.

\section{A modified contraction and convergence approach}

A gradual move to equal per capita allocations is often referred to as 'contraction and convergence' (Global Commons Institute, 2000): a contracting global annual emissions budget, with national allocations converging to equal allocations per person everywhere. This basic principle has been promoted by India and found support in recent times in Europe, and 
variations of the approach have figured in recent reports on the way forward for global climate negotiations (Stern, 2008; Commission on Growth and Development, 2008). Allocations would decrease continually for countries above the per capita global average. For countries below the average they would increase for some time - albeit typically at a rate slower than unconstrained emissions growth - before decreasing in line with the global (average) emissions.

\section{In considering principles for allocating emissions entitlements and thus sharing the burden of mitigation effort, it is important to remember that these entitlements would be tradable between countries.}

Equity in this system is addressed simply and transparently. Slow convergence favours current high emitters as it preserves current patterns for longer. Fast convergence favours countries that are now below the global average, as it allows their allocations to grow faster until reaching the (falling) global average. Thus the convergence date becomes the main equity lever in the system.

An important modification to a pure contraction and convergence system concerns rapidly growing middle-income countries, especially those that are already close to the global average per capita emissions, such as China. They would find it difficult to immediately stop and reverse the growth in per capita emissions. To enable these countries to come on board an international agreement immediately, 'headroom' would need to be provided in emissions allocations for a transitional period, to allow for a more gradual adjustment. Emissions allocations could, for example, be linked to actual growth of the economy, making them 'intensity targets' for a limited period of time.

In the Garnaut Review (2008), the rule considered was that developing countries' emissions allocations would grow at half the rate of their GDP, if this is greater than the growth in allocations under direct convergence. The 'headroom' rule would apply until 2020 or until developing countries reach the developed country average per capita allocations, whichever occurs first. Emissions growth at half the rate of GDP growth is implied by China's announced goals for reductions in energy intensity and its commitment to increase the proportionate role of low-emissions energy sources, and that could be an important factor in making the system work for the world's largest emitter.

Starting levels of emissions from which countries converge are also important. In the Garnaut Review model, convergence begins in 2013. For Annex I (developed) countries that ratified the Kyoto Protocol, the starting point is their Kyoto target levels, so that countries do not gain an advantage from not complying with Kyoto. The one exception to this is successor states to the former Soviet Union, whose Kyoto targets are well above their business-asusual levels. The former Soviet Union, the United States and all non-Annex I (developing) countries converge from their no-mitigation levels in 2012.

Computations undertaken for the Garnaut Review, using 2050 as the convergence date and the rules sketched above, imply a reduction of developed countries' average emissions entitlements, compared to 2000 levels, by around $15 \%$ at 2020 and around $75 \%$ by 2050 (Garnaut, 2008, chapter 9). This is for a global emissions trajectory consistent with stabilisation at 550 part per million (ppm) $\mathrm{CO}_{2}$-equivalent. For a more ambitious global trajectory consistent with stabilisation at 450ppm, developed countries' average emissions entitlements are reduced by around 30\% (2020) and 85\% (2050) compared to 2000 levels. Within the group of developed countries, reduction numbers are differentiated because of differences in starting levels (Kyoto target levels or 2012 projected actuals) relative to 2000 levels; the starting levels of emissions per capita, with high emitting countries subject to greater reductions; and projected population growth, with absolute reductions greater for countries with low or negative population growth.

Developing countries as a group in this model increase their emissions entitlements to 2020 by around $90 \%$ from 2000 levels and by around 20\% compared to 2012 levels. 2050 entitlements are 5\% below 2012 levels under the 550ppm scenario, and 45\% below 2012 actual levels (though still above 2000 levels) under the 450ppm scenario. Individual developing countries' growth or contraction of entitlements differs strongly, in the longer term depending especially on the starting level of per capita emissions and population growth, and in the short term to an extent on GDP growth rates.

In considering principles for allocating emissions entitlements and thus sharing the burden of mitigation effort, it is important to remember that these entitlements would be tradable between countries. That is, individual countries would be able to remain above their allocated levels by buying extra allocations from other countries that in turn remain within their allocations. Trading is a prerequisite for overall economic efficiency of the scheme, as it allows the price to equilibrate internationally. It would be particularly important in the transition towards equal per capita entitlements, when it may not be feasible or affordable in particular economies to change existing systems fast enough to reduce emissions in line with contracting emissions allocations, while other countries may find that with policy action they can remain comfortably below their allocations.

In the longer term, very low per capita emissions levels globally would make large deviations from the global per capita average for large emitters infeasible, but nevertheless there may be some countries that continue at significantly 
different per capita emissions levels due to structural reasons. For example, countries that are home to export industries that produce emissions even with advanced low-emissions technologies - possibly including some forms of agriculture and mining - would cover their excess emissions through purchases of emissions entitlements from countries that do not have these industries and that import the emissionsintensive goods.

\section{A transition period for developing countries}

The period up to 2020 should be regarded as a transition period for developing countries. This is reflected in the Garnaut Review proposals in two ways. First, as already mentioned, emissions are allowed to grow to 2020 in developing countries at half the rate of GDP. 2020 emission entitlements in developing countries are about 10\% below business-as-usual levels, with the corresponding figure for developed countries implying a much greater reduction below business-as-usual.

Second, all high-income countries as well as China, because of its financial capacity and global status as the world's largest emitter and emerging superpower, would be required to submit themselves to binding economy-wide emissions constraints. Other developing countries, however, should be required only to take on one-sided commitments until 2020. A one-sided commitment allows a country to benefit from the international sale of purchases if it exceeds the target but it is not forced to buy permits if it fails to meet its target. This no-loss arrangement for developing countries would again help facilitate developing countries' participation.

Least developing countries would not be asked to sign up to economy-wide targets at all, but would be expected to participate in relevant sectoral agreements (see below), and would continue to host Clean Development Mechanism (CDM)-type offset projects. The CDM would thus become, as it should be, a mechanism to benefit the least developed countries and not an arrangement to engage the giants of the developing world; even so it would need to be strengthened compared to today's arrangements. Overall, developing world emissions are growing so rapidly that reductions in their emissions compared to business-as-usual are needed in addition to absolute reductions in developed countries, and not, as under the CDM, as a substitute for reductions in developed country emissions.

\section{Complementary commitments}

Other policy mechanisms besides emissions targets and trading will be needed to achieve comprehensive international mitigation action at sufficient speed. They consist principally of commitments by high-income countries to make funding available for technology development and for developing countries to deal with climate change impacts, but also of commitments to sectoral emissions taxation by all countries that have significant industries producing emissions-intensive traded commodities.

First, a global agreement on minimum commitments to investment in new low-emissions technologies is needed to ensure an adequate level of funding of research, development and commercialisation. Energy research and development funding have fallen over time, despite the clear need to invest in new technologies to support the shift to a decarbonised energy system. Only recently has technology research funding received greater attention, with a number of funding initiatives launched. Widespread implementation of national emissions targets and emissions pricing would not fully take care of the technology development funding, because of the public good aspects of many new technologies, and because markets for clean technologies are missing in developing countries at least in the interim. The Garnaut Review proposed an International Low-Emissions Technology Commitment requiring high-income countries to allocate a small proportion of GDP above a threshold. They would retain flexibility in the use of funds provided, which could be spent domestically or abroad, on public funding for low-emissions research and development, for technology commercialisation, or to kick-start the mitigation efforts of developing countries. Given the need to support developing country mitigation, the Garnaut Review proposes that a minimum proportion of the commitment be expended in developing countries, say 50\%. An annual global amount of US $\$ 100$ billion is proposed, which would today require the 50 richest countries to contribute on average $0.24 \%$ of their GDP to technology funding.

\section{Achieving effective global climate change mitigation action will be extremely difficult, and time is running out to meet ambitious targets for atmospheric greenhouse gas concentrations.}

Second, sectoral agreements would seek to ensure that the main trade-exposed, emissions-intensive industries face comparable carbon prices across the world. Such sectoral agreements, with broad international participation, would ensure that countries which lacked economy-wide targets, such as the least developed countries, would not achieve an unfair advantage in trade in emissions-intensive activities. They would thereby help avoid economic distortions and political pressures in those countries that implement carbon pricing ahead of others, because the fear of 'carbon leakage' - that is, the artificial movement of industrial activities to countries that do not impose carbon penalties - would be 
alleviated. Sectoral agreements should be kept simple and focused on ensuring the emergence of appropriate and comparable price signals. In the absence of economy-wide emissions pricing, each government would at a minimum impose a carbon tax on the main producers in each industry producing emissions-intensive tradable goods. This common tax rate in itself does not allow differentiation of commitments between countries, but differentiation would not generally be necessary in industries where producers are part of a global market. National governments would keep the revenue, giving them an incentive to follow through with the commitment. Sectoral agreements would apply to key traded energy-intensive commodities, including metals, but the same principles could also apply to international civil aviation and shipping, and, in a different context and with greater institutional difficulties in implementation, land-use change and forestry emissions.

Third, an International Adaptation Assistance Commitment would provide new adaptation assistance to developing countries that join the mitigation programmes. Adaptation needs will differ strongly between countries, with activities in the core development agenda generally also beneficial in helping to deal with climate change impacts, and it is difficult to estimate the financing needs for future adaptation. Given the close similarities between the development and adaptation agendas, it is advisable not to force a division between the two, and there is no need for a new global adaptation financing infrastructure. Instead, developed countries should commit to providing adaptation support to developing countries in addition to current and planned development assistance. In the Pacific region, enhancing labour mobility in the region will be particularly important to help economies diversify and insure against climate change risk.

\section{Conclusions}

Achieving effective global climate change mitigation action will be extremely difficult, and time is running out to meet ambitious targets for atmospheric greenhouse gas concentrations. Nevertheless, it is possible to construct systems that 'add up' to the required global effort, and that should be broadly acceptable to the majority of countries, given increased realisation of the gravity of climate change risks. Here we have outlined a system of near-global coverage of efficient emissions control policies, geared in particular to facilitate early developing country participation in reducing emissions below business-as-usual levels, a fundamental precondition for effectively limiting global emissions.

It has as its centerpiece national quantitative commitments, with international tradable emissions entitlements derived from a model of gradual convergence to equal per capita emissions entitlements. For a transition period, extra headroom would be allocated to fast-growing developing countries, and most developing countries would have 'one-sided' commitments that safeguard them against any unexpected difficulties in meeting targets. These provisions could make the system attractive to developing countries. Alongside quantitative commitments stand effective sectoral agreements in the short term, and commitments by developed countries to finance technology development and deployment as well as adaptation in the context of development.

Such a system would operationalise the principle of common but differentiated responsibilities in a framework that requires and incentivises effective and efficient mitigation action from all countries in the near future, but that differentiates the effort in line with development status. It will always be possible to construct different systems, including ones that benefit particular countries by easing the burden placed on them, but any system put forward will have to add up to achievement of a global environmental outcome, while being broadly acceptable to most countries. 1 This article draws heavily on the report by the Garnaut Climate Change Review (Garnaut,
2008), especially chapter 9 and also chapter 10 .

\section{References}

Bhagwati, J. (2006) 'A global warming fund could succeed where Kyoto failed', Financial Times, 16 August

Commission on Growth and Development (2008) The Growth Report: strategies for sustained growth and inclusive development (conference edition), Washington, DC: International Bank for Reconstruction and Development/World Bank

Cooper, R.N. (2000) 'International approaches to global climate change', World Bank Research Observer, 15 (2), pp.145-72

Garnaut, R. (2008) The Garnaut Climate Change Review, Melbourne: Cambridge University Press, also available at www.garnautreview. org.au

Garnaut, R., S. Howes, F. Jotzo and P. Sheehan (2008) 'Emissions in the platinum age: the implications of rapid development for climate change mitigation', Oxford Review of Economic Policy, 24 (2)

Global Commons Institute (2000) 'GCl briefing: contraction and convergence', available at www.gci.org.uk/briefings/ICE.pdf, originally published as Meyer, A. (2000) 'Briefing: contraction and convergence', Engineering Sustainability, 157 (4), pp.189-92

McKibbin, W.J. and P.J. Wilcoxen (2002) Climate Change Policy after Kyoto: blueprint for a realistic approach, Washington, DC: Brookings Institution

Nordhaus, W. (2008) The Challenge of Global Warming: economic models and environmental policy, New Haven, Connecticut: Yale University Press

Pizer, W.A. (2002) 'Combining price and quantity controls to mitigate global climate change', Journal of Public Economics, 8, pp.409-34

Stern, N. (2008) Key Elements of a Global Deal on Climate Change, London: London School of Economics and Political Science 